\title{
Transparent conductive materials head toward the post-Si era
}

www.tcm2012.org

$\mathbf{O}$ ver the past few years, there has been a significant growth of interest in both fundamental research and device applications based on transparent conductive materials (TCMs). This class of wide-bandgap materials is finding its way into a variety of cutting-edge applications in various fields, including solar cells, gas sensors, electrochromic materials, thermochromic materials and smart windows, and in architectural coatings as well as in organic light-emitting diodes, liquid-crystal and high-definition displays, all of which are regarded as the main candidates for the forthcom- ing "post-Si" electronics era.

Driven by worldwide research activities that range from fundamental physics to materials fabrication and TCM-based device development, the International Board Members of the TCM symposium (formerly TCO), following the success of the TCO2006, TCO2008, and TCM2010 conferences, have decided to organize the 4th International Symposium on Transparent Conductive Materials (TCM2012), to be held at the same location in Crete on October 21-25, 2012.

The TCM2012 organizing committee members are George Kiriakidis of the In- stitute of Electronic Structure and Laser/ Foundation for Research and Technology-Hellas (FORTH) and University of Crete, Greece; Giorgio Sberveglieri of the National Research Council (CNR) and University of Brescia, Italy; Yuzo Shigesato of Aoyama Gakuin University, Japan; David Ginley of the National Renewable Energy Laboratory, United States; and Bernd Szyszka of the Fraunhofer-Institute for Surface Engineering and Thin Films, Germany.

The symposium is endorsed by the Materials Research Society and the European Materials Research Society.

YUCOMAT 2012 to be held in Herceg Novi

www.mrs-serbia.org.rs

$\mathbf{T}$ he Materials Research Society of Serbia will hold its Fourteenth Annual Conference - YUCOMAT 2012on September 3-7, 2012, at the Hunguest Hotel Sun Resort, Herceg Novi, Montenegro.

The conference will feature five symposia on advanced methods in synthesis and processing of materials, advanced materials for high-technology application, nanostructured materials, eco-materials and eco-technologies, and biomaterials. Invited plenary lectures along with oral and poster presentations are planned. The official conference language is English.
Abstracts, no longer than 10 lines, and registration form should be submitted by May 31, 2012. The conference program and instructions for manuscript preparation will be sent to registered participants by July 1, 2012.

Awards will be given to authors (preferably young members under age 35 ) of the best oral and poster presentation at the conference, and also the authors of highly rated $\mathrm{PhD}$ and $\mathrm{MSc}$ theses defended between two conferences. The benefits include free registration at the next YUCOMAT conference.

An exhibition of synthesis and char- acterization equipment and tutorials on especially significant topics for young researchers are planned to be held during the conference. The traditional cocktail party on Monday evening and excursions on Wednesday (Dubrovnik, Croatia) and Thursday (Boka Kotorska Bay) afternoons will be organized.

YUCOMAT 2012 is endorsed by the Materials Research Society and the Federation of European Materials Societies.

For more information, access www. mrs-serbia.org.rs or contact Aleksandra Stojicic, Conference Secretary, yucomat@ mrs-serbia.org.rs.

Course on "Materials for renewable energy" to be held in Italy www.ct.infn.it/ terrasi/erice2012.html

$\mathbf{M}$ aterials for renewable energy will be the special topic of the International School of Solid State Physics, to be held on July 18-28, 2012 in Erice, Italy. Lynn Orr (USA) will provide a global overview and and John Poate (USA) will cover the topic of the critical materials issue for the energy world. Other special lecture topics include solar wa- ter splitting (Laura Meda, Italy), carbon capture and recycling for energy storage (Jacques Amouroux, France), and the smart grid (Dave Ginley, USA), along with ample coverage of various aspects of photovoltaics. Additional lectures will address various energy sectors such as wind, geothermal, and nuclear power.

The directors of the course are Gin- ley and Poate, Emanuele Rimini (Italy), Abdelilah Slaoui (France), and Antonio Terrasi (Italy). The course is endorsed by the Materials Research Society and the European Materials Research Society.

The registration deadline is May 31, 2012. See website www.ct.infn.it/ terrasi/ erice $2012 . \mathrm{html}$ for more information. 